\title{
As subjetividades coletivas e as províncias prático-hermenêuticas da vida social
}

José Maurício Domingues*

https://orcid.org/0000-0001-9729-9528

Sistemas, sociações, províncias, campos

A discussão sobre a maneira como os sistemas sociais ocupam setores específicos da vida social é relativamente antiga e tem sido retomada de maneiras variadas na sociologia ${ }^{1}$. Sua primeira versão explícita se encontra realmente na diferenciação de "esferas de valor" na modernidade - e daí projetada de maneira algo anacrônica no passado - proposta por Weber ([1916/1917-1920] 1988, pp. 542-567) em sua discussão das religiões mundiais. De alguma maneira o tema foi recorrentemente enunciado nas teses sobre a crescente divisão do trabalho social que levava à diferenciação da sociedade em ramos distintos de atividade, das quais Durkheim ([1893] 2013) foi expressão sistemática, o que veio mesmo a constituir-se em uma ideologia sociológica, de tanto foi repetida e no fim das contas já não questionada. Em outras correntes sociológicas, o tema se apresentou: na obra de Simmel ([1908] 1992), com seus variados "círculos" de "sociação" (Vergesellschaftung); e em Schutz ([1945] 1962), com as "províncias finitas de significado" fenomenológicas dentro do "mundo da vida" de cada indivíduo (com suas "múltiplas realidades" e "zonas de relevância"), tal qual se põem a cada consciência. Mais claramente na filosofia,

* Universidade do Estado do Rio de Janeiro, Rio de Janeiro, Brasil.

1. Este artigo contou com o apoio do CNPq, da Faperje da Fundação Alexander von Humboldt. Agradeço a Monica Herz os comentários. 
podemos incluir Wittgenstein ([1953] 2009) nesse movimento geral, com sua lata noção antimetafísica de “jogos de linguagem”, de cunho mormente prático, o que seria o reverso complementar de Schutz, com seus variados universos de sentido hermenêutico (significado), ao contrário do que muitas das interpretações do filósofo austríaco tendem a fazer (na medida em que, equivocadamente a meu ver, insistem na dimensão da linguagem, não obstante sua óbvia importância). Afinal, de linguagem é a locução adjetiva que qualifica o substantivo jogos, conquanto a rigor não se deva forçar o argumento em uma ou outra direção, como veremos adiante.

Esse debate assumiu forma robusta na teoria sociológica a partir de meados do século Xx. Aí se destacaram alguns autores, fornecendo respostas mais rigorosas a essa temática, que se insinuava como crucial para a análise social.

Em primeiro lugar, Parsons ([1951] 1979), com a multiplicidade de sistemas sociais como "sistemas de ação" (inclusive implicando atores coletivos) que teciam a sociedade inclusiva, com a diversidade de áreas de interação social mais ou menos estabilizadas e sobretudo as de longo prazo cumprindo papel importante. Cada uma delas implicava indivíduos tomados como "feixes de papéis e status" e com "disposições-necessidades" internalizadas pela personalidade que compartilharia valores e normas como a "cultura" e a "sociedade". O "esquema cebola" dava expressão a isso, estendendo-se pela totalidade da vida social. Tudo isso seria analiticamente concebido. Parsons em parte se inspirava naquela múltipla definição de "sociação" simmeliana, conquanto não explicitamente, e sua conformação de indivíduos multifacetados. Isso se manteria, apesar da mudança geral de paradigma, quando Parsons (1961) optou pelo "esquema Agil”, com suas quatro funções sociais e cada vez mais rigidez, nas décadas subsequentes de seu desenvolvimento teórico. Ao fazer de seus "atores coletivos" - que originalmente tendiam a abarcar todos os sistemas sociais (Parsons, [1951] 1979, pp. 19, 61, 193-196) - apenas uma versão dos sistemas sociais - aquela que implica centros decisórios e fronteiras claras, como as empresas econômicas (Parsons e Smelser, 1964, pp. 14-15) -, de qualquer forma Parsons descartou intuições anteriores que lhe poderiam ter aberto uma via inovadora para sua análise dessa multiplicidade que tece a vida social, postulando a ideia de coletividades variavelmente centradas como agentes.

Bourdieu retomou tanto a visão weberiana da diferenciação - a partir do "campo religioso", de maneira explícita (Bourdieu, 1971) - quanto a multiplicidade dos sistemas sociais de Parsons - embora sem nunca citá-lo nessa conexão, sua obra certamente não permaneceu desconhecida do autor francês. Com isso chegou à sua teoria dos "campos", mais ou menos formalizada em As regras da arte (Bourdieu, 1992), se bem que em quase todos os seus escritos o tema apareça, com pequenas variações vinculadas a sua abordagem inspirada nas ideias de Bachelard sobre como 
teorias devem funcionar, sem excessiva formalização, a seu ver. Os campos recobrem o "espaço social" (Bourdieu, 1984), recortando-o e implicando sistemas internalizados de "habitus" específicos a cada campo, cada qual com suas formas de "capital" (que oscila ao tratar reificando como um objeto do qual os atores podem se apropriar, como na economia clássica e na neoclássica, ou como uma relação, no sentido de Marx em $O$ capital) e sistema de (quase parsoniana) "disposições". As diversas formas de capital podem ser, no obscuro estilo estruturalista, transformadas de um capital para outro mediante regras de homologia. Cada campo tem, portanto, sua lógica própria, mas, afora sua inserção em um espaço social genérico - marcado pela distribuição dos indivíduos em posições que conformam classes sociais, "no papel" enquanto tais, isto é, incapazes elas mesmas de ação -, não se sabe como efetivamente se relacionam. Não é de modo algum claro como aquelas homologias e regras de transformação têm lugar, nem como as classes os atravessam (ou não), nem muito menos qual exatamente o papel dos atores nesse processo. Observe-se ainda que a "lógica da prática", embora tampouco muito claro seu significado, comparece na teoria dos campos e da ação de Bourdieu (1980), sob a influência de Wittgenstein.

Enfim, no que nos interessa aqui de maneira direta, na obra de Luhmann o tema é retomado, em especial quando ele deixa sua teoria - ainda bastante influenciada por Parsons - dos "sistemas abertos", em favor da dos "sistemas fechados", inspirada em Maturana e Varela. O conceito de "fechamento operacional" dos sistemas, que em sua "autopoiesis" se reproduzem a partir de seus próprios elementos internos e se relacionam apenas por meio de "acoplamentos" com outros sistemas sociais, em uma sociedade cada vez mais diferenciada, terminou por fornecer o cerne de sua concepção teórica. Cada sistema dispõe assim de uma lógica binária - sim/não - própria e tudo que não diz respeito a ele é apenas ruído externo e "irritação", necessitando ser traduzida para a linguagem interna do sistema para poder ser tratada de maneira adequada, ainda que seletiva e transformada. $O$ direito, a política e a economia são os sistemas que parecem mais bem adequados, em sua reificação, à teoria altamente reificada de Luhmann (1998), que autopoieticamente somente é capaz de lidar com a realidade empírica mediante sua tradução em sua própria linguagem. Paradoxo produtivo ou tautologia inútil, cabe perguntar.

É então essa a discussão que quero articular neste texto. Trata-se de propor uma articulação teórica calcada na teoria da subjetividade coletiva que venho desenvolvendo em diversas publicações (Domingues, 1995; 1999, capítulos 1 e 2; 2004, capítulos 1-2; 2016, capítulo 1; 2018a). Irei assim mobilizar o conceito de subjetividade coletiva para dar uma resposta mais adequada às questões levantadas e de alguma maneira respondidas pelos autores que introduzi acima, sobretudo na medida em que os conceitos propostos por eles evidenciam deficiências por vezes 
graves, as quais creio ser possível ultrapassar nos quadros teóricos com que me moverei nas páginas seguintes.

Subjetividades coletivas múltiplas como sistemas sociais de interação (interna e externamente) com causalidade própria - coletiva -, as quatro dimensões analiticas de cada um deles - hermenêutica, material, do poder e espaço-temporal - e os princípios de organização e antagonismo que estruturam suas interações, bem como as relações desses sistemas com os indivíduos e suas personalidades, configurando normas e regras, estarão no centro da elaboração teórica que proporei. Além disso, o papel dos agentes, indivíduos e subjetividades coletivas, nos processos sociais sobre os quais nos debruçamos, regidos por formas variadas de reflexividade (não identitária, prática, racionalizada), no plano individual e coletivo, será decisivo. Eles medeiam ademais entre os diversos sistemas sociais que se põem comoprovincias prático-hermenêuticas, não apenas tal qual aparecem às consciências individuais, porém na forma como se tecem no curso das interações sociais, como são por elas estruturados e balizados, bem como as reproduzem, mediante sua reiteração mais ou menos completa. Como veremos, busco aqui sintetizar também as intuições seminais de Schutz e Wittgenstein.

Todavia, em vez de apresentar a questão de maneira apriorística, tratarei de expor as soluções conceituais propostas por meio da análise do Estado e dos sistemas políticos estatal e societal, bem como de suas ligações com a vida social em geral, retomando análises também desenvolvidas alhures (Domingues, 2019). Na conclusão, poderei então de maneira mais clara formalizar algumas das aquisições conceituais que creio que a análise nos permitirá.

\section{A dimensão política e o Estado}

Antes do surgimento da modernidade, podemos falar de várias maneiras como o poder social se apresenta, organizado de acordo com diversos sistemas sociais, com suas instituições e elementos imaginários (em que se entretecem os diversos elementos simbólicos-hermenêuticos que emprestam sentido à vida social) com variadas características. Com o surgimento da modernidade, então, um sistema social específico se diferencia, ao qual se pode atribuir a definição de dimensão política da modernidade, com suas instituições e imaginário específicos. $\mathrm{O}$ poder emerge e se organiza na modernidade em várias outras dimensões e sistemas sociais também, como a economia, dentro das empresas, nas relações entre as classes, ou nas famílias, entre homens e mulheres, e daí por diante. Será nessa dimensão política, específica, separada em princípio do restante da vida social, em que as decisões afetam as "sociedades", isto é, os amplos sistemas sociais recortados pelos estados-nação ou nacionais, que o poder aparecerá de forma mais destacada e nítida. É verdade que o 
liberalismo quis delineá-lo como atinente tão somente à aplicação das leis, abstratamente universais, produzidas pelo legislativo e vigiadas em sua efetividade pela polícia e pelo judiciário, mas logo a dinâmica da vida social trouxe para dentro dele os elementos concretos que cintilavam do outro lado daquilo que se queria definir como a dimensão política. Ademais, o Estado logo se caracterizou (e as ciências sociais assim o consagraram, realisticamente, trocando no caso Locke por Hobbes) como sede do poder, da dominação e do comando sobre o conjunto dos agentes sociais, inclusive e particularmente no que tange ao poder executivo.

Essa definição da dimensão política nada tem a ver com a categoria de Schmitt ([1932] 2009) de "o político", a qual se disseminou pela teoria política na segunda metade do século xx, com sua de fato ontologização (como se o conflito lhe fosse intrínseco, o que é verdade, mas não absolutamente, pois a cooperação aí joga também papel decisivo). Ao contrário, não quero separar "a política" comezinha, diuturna, de uma suposta profundidade de "o político". Trata-se na verdade do que Bourdieu (2015) chamou de um "campo" (ao lado do qual posicionou o campo jurídico) e aqui chamo de dimensão política. Esta se entretece por inúmeras interações, de diversos tipos, fundadas em princípios de organização ou antagonismo. No caso dos primeiros, incluem-se a coordenação por meio seja do "comando" - calcado na "hierarquia", vertical; da "colaboração voluntária", calcada na "rede"; assim como, por vezes, de relaçôes de "intercâmbio voluntário", calcado no "mercado", internamente - via corrupção, por exemplo - e externamente - com organizações econômicas. No caso da segunda, o conflito, através da luta, e a competição, via emulação, tecem os processos políticos. Além disso, a dimensão política é muito ampla. Ela abarca a produção e a aplicação das leis, portanto se define pela própria existência da cidadania e dos cidadãos, que são a fonte imaginária última das instituições modernas - a começar pela Constituição -, assim como o aparelho de dominação e coerção constituído pelo Estado. E tem no sistema politico o fulcro de seu funcionamento.

De modo geral, tem-se identificado sistema político com sua expressão estatal - o parlamento e o executivo, com suas burocracias e partidos, com o judiciário ocupando outra dimensão, isto é, constituindo outro "campo". No máximo, como fez Easton (1965), fala-se de um sistema "parapolítico" do outro lado da divisão entre Estado e sociedade; em geral nem isso. É verdade também que Gramsci ([1929-1935] 2001), com seu "Estado ampliado" ou "sociedade civil-sociedade" política, algo por vezes não tão claro, e Habermas (1992), retomando o tema da "sociedade civil" e da "esfera pública", ademais visando a soluções de construção baseadas no "consenso" comunicativo, ampliaram a noção de sistema político (retomando em parte autores como Tocqueville e Mills). Por seu turno, o feminismo e a teoria dos movimentos sociais chamaram a atenção para aquele que, tudo somado, 
podemos chamar de um "sistema político societal”. Em suma, a dimensão política abarca tanto sua dinâmica na sociedade quanto no Estado. Aí se constituiu, com muitas variações e alto grau de heterogeneidade, o que podemos definir como uma dimensão conformada por um tipo específico de sistema social, que se estrutura por meio de instituições e um imaginário específicos, no qual se movem agentes individuais e coletivos. Estes são partidos, sindicatos, associações, a opinião pública, cidadãos - de forma mais, no caso dos primeiros, ou menos, no caso dos segundos, centrada, ou seja, com maior ou menor nível de identidade (autorreconhecimento) e intencionalidade. Em suma, trata-se de uma vasta província prático-hermenêutica, crucial para a vida social em seu conjunto.

Ao contrário do que sugere Parsons ([1963] 1967), retomando Hobbes e a tradição liberal, não cabe falar no que tange ao sistema político de uma "mente" da sociedade, que a dirige; tampouco, porém, é possível concordar com Luhmann (2010), que oferece uma sociologia política que soa bastante ingênua, quando, ao mesmo tempo que toma o sistema político como qualquer outro (e incapaz de cumprir funções dirigentes gerais), o vê como totalmente separado da vida social. A dobradiça estatal-societal que enquanto tal caracteriza o sistema político na verdade o lança em duas direções, embora sem dúvida o eixo estatal seja em larga medida responsável por concentrar sua dinâmica, uma vez que o poder decisório, com seus mecanismos, se encontra aí depositado. Agregue-se a isso que há entre os dois lados em foco aqueles que atuam como mediadores, facilitando, ou não, a passagem de um lado ao outro.

Há, entretanto, rodeando os dois lados do sistema político, o estatal e o societal, um amplo espectro de sistemas sociais com os quais se relacionam de maneiras várias, para muito além de meros "acoplamentos". No caso do sistema político estatal, é ele que em princípio abre e fecha os canais para a burocracia estatal, a qual, à medida que a modernidade avança, se amplia. Isso é verdade sobretudo para o executivo e mesmo para o legislativo, ao passo que o judiciário teria outros canais, próprios e específicos, que o poriam em contato, e através dele os cidadãos e as organizações societais e inclusive estatais, com os setores apropriados do aparelho estatal. É no executivo que, tudo somado, a burocracia se concentra. Sobre essa burocracia opera uma miríade de aparelhos decisórios, ministérios, secretarias, repartições etc., que são parte intrínseca do sistema político estatal, diferentemente da burocracia, a qual deve ter - no estado liberal moderno - isenção política, portanto guardando seu caráter meramente técnico-profissional. Ou seja, trata-se de outros, muito variados nos estados da modernidade avançada, sistemas sociais burocráticos - especializados em saúde, educação, política econômica, política externa, seguro-desemprego e combate à pobreza etc., etc. -, com elos variados entre si, que se subordinam em princípio - mas não inteiramente - ao sistema político. 
De forma mais imediata (contatos entre agentes societais e a burocracia, legítima e legalmente ou não - via "elos burocráticos", lobbies etc.) ou indireta (pela influência geral de classes, raças, gêneros, etnias), apresentando-se assim como um campo ou espaço de luta (Poulantzas, 1978), mas igualmente de cooperação. Em outras palavras, se a dimensão política, enquanto sistema social especializado, se caracteriza em si como uma província prático-hermenêutica, a burocracia fornece outro exemplo desse tipo de sistema social e província, em enorme variedade de expressões, cada uma em si um sistema social e província prático-hermenêutica, interligadas de maneira mais ou menos estreita ou frouxa. Assim como há mediação entre sistema político estatal e sistema político societal - eles mesmos subjetividades coletivas mais ou menos descentradas, mais centradas no caso do primeiro, menos do último -, há igualmente mediação entre sistema político estatal e aparelhos burocráticos, realizada por agentes - indivíduos e subjetividades coletivas - dos dois lados da fronteira, muitas vezes porosa e nada parecida com sistemas fechados, entre eles, embora em certas burocracias o fechamento legal e profissional seja bastante rigoroso.

Se isso é verdade para o Estado, os vínculos e inclusive a porosidade ainda o é mais para a dimensão societal do sistema político. Não há fronteiras rígidas entre sistemas sociais - embora com frequência exista certo grau de fechamento, que os agentes buscam com mais ou menos ênfase manter. Já observei acima que agentes societais podem ter contato direto com a burocracia estatal (legítima e legalmente ou não). Isso pode passar pelo sistema político societal, mas pode implicar um salto direto em direção ao Estado (por exemplo via lobby de empresas isoladas, embora em geral este mobilize, de alguma forma, agentes políticos especializados). Mais amplitude de vínculos com dinâmicas e sistemas internos sustenta o sistema político societal, em sua multiplicidade e variedade, baixo centramento e atividades infinitas, sejam sindicatos e associações, mais centrados em princípio, porém amiúde pouco articulados, sobretudo se prevalece o que Gramsci ([1929-35] 2001, pp. vol. 2, p. 1244) chamou de momento "corporativo" (voltado para interesses específicos), assim como movimentos sociais, mídias de muitos tipos e opinião pública em geral, esta consistindo particularmente em uma subjetividade coletiva altamente descentrada (Domingues, 2018b). Isso pode ter a ver diretamente com a dinâmica política stricto sensu, porém se espraia pela vida econômica, artística, esportiva, sexual, familiar, universitária e daí por diante. Ou seja, sistema social específico - ou parte de um sistema social, ou as duas coisas, se levamos em conta a ideia de "esquema cebola" de Parsons, em que muitos sistemas se entrelaçam e entrecruzam -, o sistema político societal, com seus nacos institucionais e imaginários, com seus elementos de província prático-hermenêutica, segue ainda muito se alongando e gotejando para dentro de uma miríade de outros tipos de sistemas sociais, com suas instituições e 
imaginário, suas várias províncias prático-hermenêuticas, cujo caráter se suporia não ser político, podendo, ademais, alterar-se nessa direção a qualquer momento. Da mesma forma que anteriormente observado, há mediadores - agentes de diversos tipos - entre os sistemas políticos societários e a ampla malha de sistemas sociais que põem em contato com eles. $\mathrm{O}$ mesmo se aplica a contatos diretos entre as burocracias e as subjetividades coletivas societais com as quais aquelas soem entrar em contato, prescindindo de relações com os sistemas políticos.

Note-se ainda que esses sistemas parecem bem delimitados - sistemas políticos societal e estatal, burocracias, incluindo o judiciário, neutras politicamente, sistemas societais não políticos - e, a despeito de conflitos internos e por vezes entre eles, complementares e funcionais (de onde a plausibilidade do funcionalismo e do estruturalismo). Uma vez que crises de monta se abatam sobre eles - autoproduzidas ou de origens externas -, isso tudo vai por água abaixo, burocracias assumem caráter político (o exército e o judiciário), assim como os mediadores de que falamos mais acima se autonomizam e buscam ser agentes de si mesmos. As províncias prático-hermenêuticas se embaralham e alteram sua face, autocompreensão e tarefas. Eventualmente as coisas se acalmam e, dependendo de mudança mais ou menos profunda, meros ajustes, reformas ou revoluções, se normalizam. Convém notar que, independentemente de crises, há um sem número de sistemas sociais cuja existência é a própria matéria daqueles aqui explicitamente mencionados. Os sistemas políticos e a vida social de modo geral são compostos por comitês, organizações de bases, encontros casuais, disputas e cooperações momentâneas, intercâmbios entre empresas e organizações políticas baseadas em meios monetários, trocas sexuais e brigas familiares, exemplos que são, literalmente, infinitos e cujos resultados podem sempre levar ao caos, se combinados a outros com potencial disruptivo. Todavia, isso não ocorre, os sistemas mais gerais se reproduzem e produzem o que em algum momento foi o espanto de tantos de que, entretanto, há ordem. As instituições, a rotina, imaginários compartilhados contribuem para esses resultados sempre provisórios ${ }^{2}$.

Para emprestar mais concretude à linha de raciocínio acima, tomemos o exemplo da "cultura”, como se sói chamar ampla área de atividade intelectual e artística, que na obra em particular de Bourdieu cumpre papel tão destacado como "campo" específico ${ }^{3}$. Isso inclui música, literatura, pintura e escultura, atividades editoriais,

2. Vale notar que a dimensão política desenvolve tendências de longo prazo - fortalecimento do Estado e autonomização política dos indivíduos, com que se combina uma oligarquização mais circunscrita na duração - que não precisamos tratar aqui.

3. De modo geral, um neoestruturalismo bastante estático e descritivo - afora a incompreensível gênese dos campos que o caracteriza, quase weberiana-carismática - marca a visão dos campos culturais e artísticos em Bourdieu. A exceção se encontra naquela que talvez consista em sua mais completa obra $-A$ 
meios de comunicação diversos, entre muitos outros, os quais seria ocioso citar aqui. Trata-se de uma "esfera" da vida social, para usar a expressão de Weber, que somente de maneira bastante mediata - afora produções explícitas de arte política, e nas quais mesmo assim a distância tem de se manter, do contrário o que se gera é mau discurso político - se relaciona com a dimensão política. Cultura e arte se ramificam - eles mesmos como subjetividades coletivas altamente múltiplas e de modo geral bastante descentradas que compõem essa "esfera” social, embora haja movimentos, grupos que compartilham projetos e opiniões, bem como organizações, algumas diretamente ligadas ao Estado, como teatros e orquestras - por todas as dimensões e sistemas da vida social, seja o mercado, a família, a escola etc. Há, sobretudo no que nos interessa aqui, vínculos também entre produtores culturais e artísticos mais especificamente com o sistema político societal, seja em termos individuais, por vezes pelo engajamento de grandes personalidades em suas atividades e dinâmica. Há igualmente vínculos entre as subjetividades coletivas da cultura e da arte com o sistema político estatal e com a burocracia, por vezes passando pouco pelo sistema político societal. Seja como for, a legislação tem de ser aprovada pelo legislativo e ministérios e secretarias específicas, com seus corpos de funcionários, que produzem e implementam políticas públicas voltadas para essa dilatada e variada subjetividade coletiva conformada pela "cultura" e pela arte (seja de organização e promoção, fomento ou mesmo interdição, como a censura). O judiciário também é muitas vezes chamado a vincular-se a essas atividades, ao ter que julgar casos que emanam dela e de seus agentes.

Em outras palavras, uma extensa malha de interações entre subjetividades coletivas que se interpenetram, cooperam e se conflitam caracteriza os vínculos entre o que se convencionou chamar de cultura e arte com a dimensão política. Esses processos sociais interativos de natureza política e os sistemas em que se baseiam e conformam são cruciais para esse dito "campo" ou "esfera” social particular, em sua multiplicidade, moldando assim por seu turno múltiplas subjetividades coletivas. Ao mesmo tempo, cultura e arte deitam raízes e impactam o conjunto da vida societária para muito mais além da política propriamente dita na modernidade. Numerosas "sociações", para evocar a categoria de Simmel, em diversas províncias prático-hermenêuticas se tecem destarte, algumas já inclinadas politicamente, outras longe disso.

Muitos outros "campos", "esferas", "círculos" ou "províncias" poderiam ser focalizados com esse mesmo desenho. Seria no entanto procedimento, nos quadros deste

distinção (1979) -, na qual a interação conflitiva entre os atores fornece o cerne de seu argumento e análise, inclusive com a conformação de uma dimensão espaço-temporal dinâmica, tema que se aduzirá ao desenvolvimento de minha discussão mais adiante. 
texto, desnecessário, embora interessante do ponto de vista do funcionamento de cada um. Isto posto, é hora de organizar e em parte refinar as categorias que, nas páginas precedentes, vimos em aplicação no que tange aos sistemas políticos, ao Estado e à sociedade de maneira geral.

\section{Retomando as categorias}

Chegamos então a uma definição dos sistemas sociais que conformam a vida social como subjetividades coletivas que se encontram em todos os aspectos vida social. Como sistemas de (inter)ação, entre indivíduos e entre coletividades, eles se fizeram crescentemente "especializados" com a modernidade e em parte à medida que ela avança, embora isso não seja de modo algum absoluto (por exemplo, arte e propaganda, política e economia se misturam muitas vezes); ou seja, há variáveis e instáveis processos de diferenciação, que podem passar por rediferenciações, conquanto a complexidade também crescente da vida social na modernidade seja irreversível (Domingues, 1999, capítulo 4). Essa perspectiva, em seus elementos básicos, que exemplifiquei mediante uma análise da dimensão política, nos serve a meu ver como uma alternativa mais flexível - e mais adequada, em particular no que se refere às coletividades como agentes - às cristalizações conceituais que examinei na primeira parte do texto, especialmente os populares conceitos de "esferas de valor" de Weber e "campo" de Bourdieu. Os outros elementos que carecem ser somados a essa conceitualização, que nos permitirão um quadro analítico mais completo do que chamei acima de províncias prático-hermenêuticas, serão discutidos em seguida.

A princípio, tomemos os aspectos analíticos da dimensão política. Evidentemente, saltam aos olhos as relações de poder que se articulam dentro dela e a articulam, bem como articulam a dimensão política com as outras dimensões e sistemas sociais. Mas a política depende de valores e normas em que esses se especificam diferentemente do que por vezes parece, com um maquiavelismo que pode ser uma denúncia dos interesses autorreferidos dos políticos profissionais, mas também uma justificativa destes para seu comportamento. De uma maneira ou de outra, valores e normas - inclusive de caráter jurídico, calcadas no direito moderno e traduzidas ainda mais em direito administrativo - atravessam e organizam o Estado, incluindo o sistema político estatal. Assim se estabelecem parâmetros institucionais nesse âmbito, conquanto o mesmo valha para o sistema político societário e as ramificações do direito, público ou privado, por dentro da vida social em sua totalidade. Ou seja, colada concretamente ao poder se põe a dimensão hermenêutica, na qual se tece simbolicamente o imaginário, mas também uma concretização sua em termos institucionais. Além disso, o sistema político e o Estado mais geralmente, mas deixando 
de lado o aspecto societário do sistema político, uma dimensão material - pouco tocada ou transformada pelo artesanato ou a indústria, moldada pela tecnologia e até pela ciência, a começar pelos corpos humanos - dá sustentação aos processos interativos e à constituição das subjetividades coletivas em toda sua gama. Aqui vale lembrar as ideias de "ator-rede" ou "redes sociotécnicas", sugeridas por autores como Callon e Latour (Callon, 2006), em especial de um ponto de vista metodológico. Por outro lado, não é possível reduzir as subjetividades coletivas a esse aspecto, nem lhe emprestar preponderância - nem misturar muito subjetividade humana e causalidade material. Elas são distintas substantivamente e assim devem ser tomadas conceitualmente ${ }^{4}$.

Nesse passo, é preciso aprofundar o comentário. Os agentes individuais exercem o que se convencionou explícita ou tacitamente como causalidade teleológica. Isto é, põem-se fins e os alcançam ou não, a partir de valores e de seu envolvimento cotidiano com diversas esferas de atividade, utilizando-se de meios - que podem vir a tornar-se eles mesmos fins - em condições determinadas, invariavelmente lidando com tais situações de modo mais ou menos criativo. Exercem assim um impacto causal sobre o mundo - outros agentes e o mundo material. $\mathrm{O}$ mesmo se pode dizer das subjetividades coletivas: elas exercem um impacto causal - uma causalidade coletiva - umas sobre as outras e sobre o mundo material. Mas aqui a teleologia não assume a mesma proporção ou qualidade. Pois o nível de centramento das subjetividades coletivas varia, com isso variando seu nível de intencionalidade e, portanto, o que seria a teleologia de seu movimento coletivo. Na verdade, um altíssimo nível de descentramento pode ser característico das coletividades ou sobrevir inclusive sobre aquelas em princípio mais centradas, exercendo força centrípeta sobre seus membros, indivíduos e subcoletividades, que se movem então eventualmente em direção oposta. Em suma, se os sistemas sociais de interação, as subjetividades coletivas (ou coletividades, para ser breve), se impactam causalmente, mutuamente, não se deve imaginar esse processo como calcado no modelo de um agente sempre centrado, indivíduo biológico ou coletivo - como uma firma, família, organização. Nem tampouco o efeito causal de cada um deles deriva necessariamente de seu alto grau de centramento: descentramento, dependendo dos outros agentes e do contexto, pode levar a maior impacto causal sobre outras subjetividades coletivas.

4. Trata-se aqui de discussão que remete a Aristóteles e foi retomada na modernidade, agora reproposta por Latour (2001, pp. 177-98 e 217-218) com a ideia, imprecisa, de "actante". Ele quer corretamente romper com a problemática separação entre "sociedade" e "natureza" que a modernidade instaurou. Mas sua solução é um mau ponto de partida, antes confundindo que esclarecendo. A tese de que todos os sistemas sociais têm uma dimensão material, com sua própria e específica causalidade, me parece mais adequada, o que se replica, no caso dos indivíduos, imediatamente no que diz respeito a seu corpo. 
Isso tudo é mediado, de qualquer forma, pela dimensão hermenêutica. O mundo material, incluindo os animais, mesmo aqueles muito próximos aos seres humanos (que, está claro hoje, não são de modo algum “bestas”, como se quis crer), não tem capacidade de organização simbólica e mesmo sua teleologia é limitada. O mundo material exerce assim uma causalidade específica - material - que não deve ser misturada com a da subjetividade humana, individual e coletiva. Se a tradição da teoria social precisa ser revista, não cabe introduzir indistinções que em nada nos auxiliam, antes confundem as coisas. Finalmente, temos que nos deter na dimensão espaço-temporal dos sistemas sociais, das subjetividades coletivas. Originalmente a teoria social adotou a ideia de que os agentes sociais se moviam, kantianamente, no tempo e no espaço, ambos homogêneos. Mas isso é limitado. Se tomamos a ideia de Einstein de espaço-tempo, na qual este é uma dimensão a mais daquele, sendo sua unidade heterogênea e variável, assim como seus ritmos de evolução, podemos ter uma visão mais precisa dos sistemas sociais - do sistema político e do Estado. Eles conformam, mediante as interações que os tecem e por intermédio das quais se tecem, diversas dimensões espaço-temporais, com seus ritmos diversos e por vezes contraditórios, no parlamento, nas cortes, nos escritórios, nas ruas, e daí por diante. Isso tem uma grande importância e muitas vezes é crucial para a explicação da dinâmica política (a começar pela relação entre política institucional e manifestações de rua).

Se há essa multidimensionalidade dos sistemas sociais, em especial da dimensão política, do sistema político e do Estado, os agentes que aí operam são, invariavelmente, reflexivos. Mas nesse passo convém também ser cuidadoso. Pois há tipos específicos de reflexividade, bem como de graus em seu exercício. Na maior parte do tempo todos nós simplesmente nos portamos de maneira pragmática, mobilizando nossa reflexividade prática. Nunca se trata, porém, de mera "vivência" ou “experiência”, ao contrário do que Schutz sugeriu. Essa conexão com a prática foi a grande percepção de Wittgenstein, ao falar de seus jogos de linguagem. Os sistemas sociais evidenciam-se assim como províncias prático-hermenêuticas, antes de tudo. A rotina tem grande papel em seu funcionamento, como de resto o próprio Bourdieu, mas também Giddens (1979, capítulo 2), observaram. A teleologia - prática - e a dimensão simbólica se fazem aí, de todo modo, presentes. Essa reflexividade pode ser racionalizada e então aguçada, com a atenção dos agentes se voltando para aquilo que eles fazem, com o exato intento de controlar melhor seu comportamento e suas consequências. De todo modo, consequências não intencionais se desdobram, sempre, saiba-se delas de antemão ou não. Subjacente a essas duas reflexividades encontra-se uma terceira, na verdade originária, uma reflexividade arracional, anterior e oposta à lógica da identidade, em que novos símbolos e soluções práticas emergem, 
algo que a tradição de pensamento ocidental tem dificuldade de aceitar, e que, no entanto, efetivamente ocorre.

Indivíduos e coletividades partilham todos, interativamente, dessas operações reflexivas, que atuam dentro da cabeça dos agentes individuais mas igualmente nos intercâmbios cognitivos, normativos e expressivos entre eles e as coletividades que tecem e pelas quais são conformados. Políticos profissionais, revolucionários, intelectuais públicos, artistas, engajados ou não, os ativistas de movimentos sociais e organizações não governamentais, os cidadãos em geral, partidos, organizações, associações: somos todos partícipes dessas diversas facetas da reflexividade. Em que medida normas são internalizadas pelos atores em sua "sociação" ou, mais especificamente, socialização ao longo da vida - conformando um "babitus", diria Bourdieu, arraigado ou em certos casos talvez mais leve, por sua "internalização", diria Parsons - é questão a ser empiricamente investigada. Se não são internalizadas, temos, em lugar de normas, somente regras, do ponto de vista do ator, com as quais lidará instrumentalmente, sem necessariamente de fato comprometer-se com elas.

Há, por assim dizer, uma "lógica" própria, por conseguinte, na modernidade política, bem como em qualquer província prático-hermenêutica da vida social, sem que com isso se deva supor "autopoiesis" ou "fechamento operacional", pois informações vêm de todos os lados e a manutenção dos parâmetros dos sistemas custa enorme esforço social, o que usualmente se funda em relações de poder que podem facilmente apresentar face coercitiva dura. Essa lógica é tanto prática quanto variavelmente racionalizada. Isso elimina o problema das supostas homologias entre os "campos", porquanto não sejam fechados, e recursos que se utilizam em um possam ser utilizados em outro, sem necessidade de que sejam sempre transformados, como o dinheiro, o prestígio, o poder político etc. É verdade que pode haver, com efeito, algum tipo de tradução. Sabe-se que o dinheiro compra qualquer coisa, que o poder político dobra as pessoas, que o prestígio pode ser impulsionado por ambos. Porém, isso apenas imperfeitamente no curto prazo se mostra eficaz, sendo no médio e longo prazo que essa tradução se cristaliza, apagando muitas vezes seus rastros. A porosidade é quase tendência natural entre os sistemas sociais, que os desenhos institucionais tentam conter, por vezes inclusive com sanções legais, conquanto adaptações tenham que ser feitas quando se passa da lógica de um sistema a outro.

Observemos ainda, algo já assinalado anteriormente, que as interações sociais podem ser de coordenação ou implicar antagonismo. Alianças, acordos, compromissos, projetos conjuntos se enquadram no primeiro caso. Choques, conflitos, concorrência, no segundo. Sempre passam pelasjá mencionadas formas de coordenação hierárquica, de mercado e em rede (calcadas, respectivamente, no comando, na troca voluntária e na colaboração voluntária), ou têm no antagonismo, via conflito e competição 
(fundados na luta e na emulação), seus pontos de apoio ${ }^{5}$. Uma olhada de relance à política facilmente nos descortina essa variada gama de possibilidades de interação, embora alguns autores, como Schmitt, prefiram tratar do conflito como exclusivo, ao passo que outros, como Habermas, apostam no "consenso" como saída conceitual e normativa. Coube a Gramsci ([1929-1935] 2001) mais adequadamente combinar essas duas possibilidades analíticas e substantivas, bem como seus diversos matizes, se bem que em plano antes substantivo.

Aduza-se que as formas pelas quais as interações se articulam e estabilizam, bem como os caminhos costumeiros pelos quais mudam, implicam certa inevitável reiteração, inclusive no curso de sua mudança. Memórias sociais, que são tanto individuais como coletivas, conquanto sempre um pouco heterogêneas, nesse sentido importam. Todavia, tudo em princípio pode se transformar na medida em que forte criatividade social, que, de novo, é ao mesmo tempo individual e coletiva, incida sobre esses processos, alterando mais fortemente o imaginário e as instituições. Pode até haver grandes personagens ("carismáticos", como quis Weber, ao que parece ao menos em parte seguido por Bourdieu) no surgimento das províncias prático-hermenêuticas, a começar pela dimensão política, incluindo aspectos do sistema político e do funcionamento estatal, mas esse não é nem de longe necessariamente o caso; quando eles têm relevância, isso ocorre dentro de quadros muito mais amplos, contando com a interação de um número maior de agentes, de ordem individual e coletiva. Essa é também maneira de avançar para além dos impasses do repetitivo debate sobre "ação e estrutura”. Enfim, note-se que motivações e inclinações individuais e coletivas (disposicionais, dependentes de investimentos libidinais) são cruciais na dimensão política, na estatal e em qualquer outra. Alcançar um tipo específico de poder é decisivo aí, mas a influência sem controle dos mecanismos de comando pode ser tão mais importante em muitos casos, ao contrário do que um suposto "realismo" indica ser o caso universal da política.

\section{Conclusão}

Este artigo buscou articular uma alternativa, baseada na teoria da subjetividade coletiva, a algumas das mais correntes perspectivas conceituais que tratam de sistemas sociais específicos nas formações sociais altamente diferenciadas e complexas da modernidade global. Em lugar dos conceitos de "campo" ou "esferas" (de valor e/ou práticas), mas em parte reconhecendo a pertinência desses conceitos, porquanto en-

5. Inclinações interativas perfilam, no primeiro caso, comerciar, mandar/aceitar, cooperar; no segundo, combater e sobrepor-se, bem como justificativas vinculadas a cada uma delas. 
frentam problemas teórico-empírico reais, ele propôs a concepção de subjetividades coletivas que conformam e se conformam como províncias prático-hermenêuticas e atravessam o conjunto da vida social. Como maneira de demonstrar a efetividade da conceituação proposta e elaborá-la em detalhes sem partir da exposição dogmática de categorias, o texto debruçou-se sobre a dimensão política da modernidade, com destaque para o sistema político (tanto estatal como societal) e o Estado de modo geral. Além disso, fez breve incursão pelas províncias da "cultura" e da arte. Uma teorização precisa sobre a causalidade social das subjetividades individuais e coletivas foi igualmente argumentada.

As teorias sociológicas que marcaram com força o século $\mathrm{xx}$ foram capazes de ter grande impacto nas ciências sociais e inclusive do ponto de vista público, em parte por serem capazes de organizar ou ao menos conectar-se com amplos programas de pesquisa de natureza mais empírica. $\mathrm{O}$ mesmo se verificou com seu contraponto, formalmente sociológico ou não, pelas diversas correntes do marxismo. Desde os anos 1970, porém, isso não tem ocorrido e se firmou uma desconexão entre teoria e pesquisa empírica, com o que se configurou como grandes sínteses teóricas e o que, de maneira mais fragmentada, se lhes seguiu, não obstante exceções, sobretudo na França, onde por outro lado a generalização teórica tem sido menos ambiciosa. Este texto, seguindo o exemplo de outros em que a teoria da subjetividade coletiva se apresenta como eixo conceitual, visa precisamente a superar essa disjunção, a qual tem tido consequências nefastas para a sociologia, cuja teoria acaba se apresentando como má, superficial, filosofia, ao passo que as pesquisas empíricas em seu âmbito perdem seus alicerces conceituais.

Por enfrentar um aspecto nevrálgico da discussão sociológica sobre e na modernidade, o conceito de províncias prático-hermenêuticas se posiciona como exemplar de razoável relevância nessa direção, com sua aplicação na sociologia política. Em si e ao demonstrar o potencial teórico dos conceitos que giram ao redor e complementam o de subjetividade coletiva, ajuda-nos a vislumbrar a retomada do que foi, ao longo do século Xx, um aspecto crucial das ciências sociais, no caso aqui em tela. Ademais, embora isso não tenha sido tratado diretamente neste texto, pode cumprir também papel relevante em uma reestruturação de abordagens teóricas críticas. 


\section{Referências Bibliográficas}

Bourdieu, Pierre. (1971), "Genèse et structure du champ religieuse". Revue Française de Sociologie, 12-13: 295-334.

Bourdieu, Pierre. (1979), La distinction. Paris, Minuit.

Bourdieu, Pierre. (1980), Le sens pratique. Paris, Minuit.

Bourdieu, Pierre. (1984), "Espace social et genèse de 'classe'". Actes de la Recherche en Sciences Sociales, 52-53: 3-14.

Bourdieu, Pierre. (1992), Les règles de l'art. Genèse et structure du champ litteraire. Paris, Seuil. Bourdieu, Pierre. (2015), Sur l'Etat. Cours au Collegge de France (1989-1992). Paris, Points. Callon, Michel. (2006), “Sociologie de l'acteur reseaux”. In: Akrich, Madaleine, Callon, Michel \& Latour, Bruno (orgs.). Sociologie de la traducción: textes foundateurs. Paris, Presses de Mines.

Domingues, José Maurício. (1995), Sociological theory and collective subjectivity. Londres e Basingstoke, Macmillan Press e Nova York, Saint Martin’s Press (Palgrave).

Domingues, José Maurício. (1999), Criatividade social, subjetividade coletiva e a modernidade brasileira contemporânea. Rio de Janeiro, Contra Capa.

Domingues, José Maurício. (2004), Ensaios de sociologia. Belo Horizonte, Editora UfMg.

Domingues, José Maurício. (2016), Estudos e críticas em teoria social. São Paulo, Annablume.

Domingues, José Maurício. (2018a), Emancipação e história. O retorno da teoria social. Rio de Janeiro, Civilização Brasileira.

Domingues, José Maurício. (2018b), “Public opinion and collective subjectivity: A conceptual approach". Distinktion: Journal of Social Theory, 19: 249-267.

Domingues, José Maurício. (2019), Critical theory and political modernity. Basingstoke/Nova York, Palgrave.

Durkheim, Emile. ([1893] 2013), De la Division du travail social. Paris, Presses Universitaires de France.

Easton, David. (1965), A Framework for Political Analysis. Englewood Cliffs, NJ, Prentice-Hall.

Giddens, Anthony. (1979), Central problems in social theory: action, structure, and contradiction in social analysis. Cambridge, Polity.

GramsCI, Antonio. ([1929-1935] 2001), Quaderni del carcere, vols. 1-3. Turim, Einaudi.

Habermas, Jürgen. (1992), Faktizität und Geltung. Beiträge zur Diskurstheorie des Rechts und des demokratischen Rechtsstaat. Frankfurt am Main, Suhrkamp

Latour, Bruno. (2001), Pasteur. Guerre et paix des microbes. Suivi de Irréductions. Paris, La Découverte.

Luhmann, Niklas. (1998), Die Gesellschaft der Gesellschaft. Frankfurt am Main, Suhrkamp.

Luhmann, Niklas. (2010), Politische Soziologie. Frankfurt am Main, Suhrkamp.

Parsons, Talcott. ([1951] 1979), The social system. Nova York, Free Press. 
Parsons, Talcott. (1961), “An outline of the social system”. In: PARsons, Talcott et al. (orgs.). Theories of society: foundations of modern sociological theory, vol. 1. Nova York, Free Press.

PARsons, Talcott. ([1963] 1967), “On the concept of political power”. In: Sociological theory and modern society. Nova York, Free Press.

PARsons, Talcott \& SMeLSER, Neil J. (1964), Economy and society: a study in the integration of economic and social theory. Nova York, Free Press.

Poulantzas, Nicos. (1978), L'Etat, le pouvoir, le socialisme. Paris, Presses Universitaires de France.

Schmitт, Carl ([1932] 2009) Der Begriff des Politischen. Berlim, Duncker \& Humblot.

Simmel, Georg. ([1908] 1992), “Die Kreuzung sozialer Kreise”. In Soziologie. Untersuchungen über die Formen der Vergesellschaftung. Frankfurt am Main, Suhrkamp.

Schutz, Alfred. ([1945] 1962), “Multiple realities”. In Collected Papers, vol. 1: The Problem of Social Reality. The Hague, Martinus Nijhoff.

Weber, Max. ([1916/1917-1920] 1988), “Zwischenbetrachtung. Stufen und Richtungen der religiösen Weltablehnung". In Die Wirtschaftsethik der Weltreligionen. Gesalmmelte Aufsätze zur Religionssoziologie, vol. 2. Tübingen, J. C. B. Mohr (Paul Siebeck).

Wittgenstein, Ludwig. ([1953] 2009), Philosophische Untersuchungen/Philosophical Investigations. Malden, MA e Oxford, Willey Blackwell.

\section{Resumo}

As subjetividades coletivas e as províncias prático-hermenêuticas da vida social

Este artigo articula uma alternativa, baseada na teoria da subjetividade coletiva, a algumas das mais correntes perspectivas conceituais que tratam de sistemas sociais específicos nas formações sociais altamente diferenciadas e complexas da modernidade. Em lugar dos conceitos de "campo" ou "esferas", mas em parte reconhecendo sua pertinência, o artigo propõe a concepção de subjetividades coletivas como provincias prático-hermenêuticas que atravessam o conjunto da vida social. Para demonstrar a efetividade da conceituação e elaborá-la em detalhe, o texto debruça-se sobre a dimensão política da modernidade, destacando-se o sistema político (tanto estatal como societal) e o Estado de modo geral, com breve incursão pelas províncias da "cultura" e da arte. Palavras-chave: Subjetividade coletiva; Províncias prático-hermenêutica; Campo; Esferas de valor.

\section{Abstract}

Collective subjectivities and the practical-hermeneutical provinces of social life

This article articulates an alternative, based on the theory of collective subjectivity, to some of the most current conceptual perspectives dealing with specific social systems in the highly differentiated and complex social formations of modernity. Instead of the concepts of "field" or "spheres", but partly recognizing their relevance, the article proposes the conception of collective 
subjectivities as practical-hermeneutical provinces that cut cross the whole of social life. To demonstrate the effectiveness of the proposed conceptualization and elaborate it in detail, the text focuses on the political dimension of modernity, with emphasis on the political system (both state and societal) and the state in general, with a brief foray into the provinces of "culture" and art. Keywords: Collective subjectivity; Practical-hermeneutic provinces; Fields; Value spheres.

Texto recebido em 19/10/2019 e aprovado em 29/5/2020.

DOI: 10.11606/0103-2070.ts.2020.163382.

José Maurício Domingues é professor do Instituto de Estudos Sociais e Políticos da Universidade do Estado do Rio de Janeiro (Iesp-Uerj), pesquisador do CNPq. E-mail: jmdomingues@ iesp.uerj.br. 